\title{
Partial-birth abortion - is it legally and ethically justifiable? Lessons for South Africa
}

\author{
F Jogee, LLB, LLM \\ Centre for the AIDS Programme of Research in South Africa (CAPRISA), University of KwaZulu-Natal, Durban, South Africa
}

\begin{abstract}
Corresponding author: F Jogee (faadielajogee@gmail.com)
\end{abstract}
Intact dilation and extraction is a surgical abortion procedure dubbed 'partial-birth abortion', and is deemed infanticide by conservative pro-life advocates in the USA. Despite its salutary (albeit feticidal) nature, as it is arguably less destructive than alternative surgical abortion procedures, intact dilation and extraction is federally banned in the USA. While ostensibly unrelated, the matter is germane to South Africa $(\mathrm{SA})$ as it may inform legislation and legal policy on the regulation of feticidal abortion procedures, since feticide remains unregulated by law. The objective of this article is to understand why intact dilation and extraction is proscribed, and whether proscription is justifiable in SA. Accordingly, the primary legal, medical and ethical arguments underpinning proscription are presented, followed by an examination of the veracity of each argument before gauging whether intact dilation and extraction is constitutionally and ethically justifiable in SA.

S Afr J Bioethics Law 2018;11(2):96-101. DOI:10.7196/SAJBL.2018.v11i2.623

'Partial-birth abortion' (PBA) is a US colloquialism for intact dilation and extraction ( $\mathrm{D}$ and $\mathrm{X}){ }_{1}^{[1]}$ coined by conservative pro-life advocates, who liken the procedure to infanticide. ${ }^{[2]}$ Their reasoning is founded on the erroneous belief that $D$ and $X$ constitutes the partial delivery and subsequent murder of a full-term baby. ${ }^{[, 4]}$ Conversely, $D$ and $X$ is a variant of dilation and evacuation ( $D$ and $E)_{1}^{[5,6]}$ possibly the safest procedure employed during late termination of pregnancy (LTOP), which refers to abortions that occur after 20 weeks' gestation. ${ }^{[7-15]}$ The Centers for Disease Control and Prevention have stated that on average, $1.3 \%$ of abortions in the USA are LTOPs, of which D and Xs comprise fewer than 20\%. ${ }^{[15]}$ $\mathrm{D}$ and $\mathrm{Xs}$ are carried out between 20 and 24 weeks' gestation, ${ }^{[16]}$ and typically comprise four steps: cervical dilation; breech conversion; breech extraction, excluding the fetal head; and cephalocentesis to induce vaginal delivery of the intact fetus. ${ }^{[14,17]}$ The defining feature of $D$ and $X$ is cephalocentesis, which entails the removal of the intracranial contents by way of a suction device, consequently preventing cervical injury by reducing the diameter of the fetal skull prior to intact delivery ${ }_{.}^{[9,10]}$ Hence $D$ and $X$ may be more advantageous than $D$ and $E_{1}^{[14]}$ which involves fetal dismemberment that is known to increase the risk of maternal mortality and morbidity. ${ }^{[11,12]}$

Nevertheless, D and $X$ is federally proscribed except in lifethreatening circumstances, as per the US Partial-Birth Abortion Ban Act of 2003. ${ }^{[18]}$ Failure to comply with the provisions of the Act will result in a fine, imprisonment of up to 2 years, or both a fine and imprisonment. ${ }^{[18]}$ The legality of the Act was brought before the Supreme Court in Gonzales v Carhart ${ }^{[19]}$ and scrutinised for its perceived ambiguity; the Act proscribes surgical feticidal abortion procedures comprising the substantial removal of the fetus via vaginal delivery. ${ }^{[19]} \mathrm{D}$ and $\mathrm{E}$ encompasses fetal dismemberment requiring substantial removal of the fetus through the vagina, a practice that is explicitly proscribed by the Act, and therefore $D$ and $E$ could be included under the ban, which could subsequently impose an undue burden on women by restricting their reproductive health choices. ${ }^{[19]}$ The Supreme Court found the state to hold a bona fide interest in fetal protection, and held that the Act exclusively proscribes $D$ and $X$; therefore, proscription is not unduly burdensome to women. ${ }^{[19]}$ Currently, D and $X$ is proscribed in 32 US states. ${ }^{[13]}$ Currently, the US is the only country worldwide to legally proscribe and criminalise $D$ and $X .{ }^{[14]}$

South Africa (SA)'s Choice on Termination of Pregnancy Act No. 92 of $1996(\text { CTOPA })^{[20]}$ is universally hailed as one of the most liberal pieces of legislation worldwide. ${ }^{[2]]}$ CTOPA makes provision for LTOP after 20 weeks' gestation once a physician, having consulted with another physician or registered midwife, concludes that: the patient's life is at risk; the fetus is suffering from acute malformation; or the fetus may be considerably injured upon delivery. ${ }^{[22-25]}$ However, it does not regulate feticide and abortion procedures. ${ }^{[14]}$ Consequently, abortion procedures may be employed at the discretion of a physician, without legal repercussions. ${ }^{[14]}$ This highlights the importance of this evaluation of the reasons for the proscription of $D$ and $X$, prior to determining whether it is constitutionally and ethically justifiable in SA. ${ }^{[14]}$ The outcome of this evaluation could inform legislation and policy on the regulation of feticide in SA. ${ }^{[14]}$

\section{Fetal pain}

Medical evidence suggests that the structures required to experience pain begin to manifest during the first trimester, ${ }^{[14,26]}$ and are fully developed towards the end of the second trimester. ${ }^{[14,27]}$ The application of painful stimuli triggers a stress response between 18 and 20 weeks' gestation, possibly causing neurodevelopmental deficiencies, ${ }^{[14,28,29]}$ hence the use of anaesthesia and analgesics during fetal surgery. ${ }^{[14,30]}$ Nonetheless, the fetus supposedly requires up to 50 times the regular adult dosage of anaesthesia, since the placental membrane creates a barrier between woman and fetus. ${ }^{[1,33]}$ 
When anaesthesia is administered to the woman, it filters through her blood stream before infiltrating the placental membrane to have an effect on the fetus. ${ }^{[14,31]}$ Consequently, the woman would require a dosage detrimental to her health. ${ }^{[14,31]}$ Therefore, the fetus cannot receive the dosage it requires to be anaesthetised during the $\mathrm{D}$ and $\mathrm{X}$ without jeopardising the health of the woman. Moreover, the neurotransmitters mediating pain present during the second trimester, ${ }^{[14,32]}$ yet neurotransmitters diminishing pain only appear in the third trimester; subsequently, fetuses aged between 20 and 30 weeks are purportedly vulnerable to pain. ${ }^{[14,32]}$

Conversely, conflicting medical evidence has shown that fetal pain is improbable without the essential biological and neuroanatomical structures facilitating pain. ${ }^{[1,19]}$ The feeling of pain is dependent on a thalamocortical connection; supporting evidence illustrating fetal thalamocortical connection is limited. ${ }^{[14,33]}$ Pain necessitates the perception of noxious stimuli, requiring functional thalamocortical connections..$^{[14,31]}$ However, thalamocortical fibres only manifest during the final trimester; ${ }_{i}^{[1,30]}$ therefore, fetal pain is doubtful before then. ${ }^{[14]}$ Regardless, proscription of $D$ and $X$ on the grounds of fetal pain is untenable. ${ }^{[14]}$ Even if fetal pain were irrefutable, all feticidal surgical TOP procedures available between the first and third trimester could be subjected to proscription if fetal pain develops during the first trimester ${ }^{[33]}$ and is definitive by the second, ${ }^{[14,27]}$ consequently imposing an undue burden on women and physicians. Accordingly, the argument is indefensible, bearing in mind that although a pro-life alternative to abortion, such as adoption, might resolve the issue, this is not always feasible. ${ }^{[14]}$

\section{Informed consent}

In the US case of the National Abortion Federation et al. v Ashcroft, ${ }^{[34]}$ physicians ostensibly repudiated patient autonomy by failing to properly solicit informed consent for $\mathrm{D}$ and $\mathrm{X}$. During the informedconsent process, the physicians allegedly employed hyper-technical medical terms that were unintelligible to patients, evaded questions or deliberately withheld information pertaining to fetal pain, or reassured patients that anaesthesia would ensure painless fetal demise. ${ }^{[14,31]}$

South Africans enjoy the constitutional rights to bodily integrity, ${ }^{[35]}$ including the rights to self-determination, healthcare ${ }^{[36]}$ and access to information, ${ }^{[37]}$ which are statutorily protected by the National Health Act (NHA) No. 61 of 2003. The NHA legally and ethically obligates physicians to solicit informed consent before undertaking any medical examinations, treatments or surgeries. ${ }^{[14,38]}$ Patients must be informed of every medical or surgical procedure relevant and available to them, including the benefits, risks, costs and possible consequences of each option. ${ }^{[14,39]}$ Physicians are also required to inform patients of their right of refusal, and the possible risks, implications and obligations accompanying it. ${ }^{[14,39]}$ During the informed-consent process, patients must be informed in a manner appropriate to their literary levels. ${ }^{[14,40]}$ Physicians must ensure that patients comprehend the information before voluntarily consenting to or refusing treatment, surgery or examination. However, physicians may invoke the therapeutic privilege enabling them to withhold important medical information that would normally be disclosed during the informed-consent process until after medical assistance has been rendered to the patient, provided disclosure is within the patient's best interest. ${ }^{[14,38,41]}$
In the case described above, it can be argued that the physicians repudiated patient autonomy, as the patients did not fully consent to the procedure, and therapeutic privilege would not be applicable under the circumstances. ${ }^{[14]}$

The presumption that a physician would deliberately repudiate patient autonomy for $\mathrm{D}$ and $\mathrm{X}$ is specious. ${ }^{[14]}$ Providing comprehensive information concerning feticide to a patient requesting abortion is difficult for the physician to do, and it can be hard for the patient to hear. ${ }^{[14]}$ Physicians are required to convey the benefits, risks and implications of each procedure available to the patient, enabling the patient to make an autonomous healthcare decision, thereby upholding the patient's constitutional and statutory rights. ${ }^{[14,39]}$ If the patient wishes to be scrupulously informed about each procedure, the physician should oblige, provided it is within the patient's best interests; however, the physician is not legally obligated to do so. ${ }^{[14]}$ One also has to take into consideration that the informed-consent process could be compounded in emergency situations, given the time-sensitive nature of the event. ${ }^{[14]}$ Likewise, the process may be more difficult for physicians tending to patients in the public sector, in light of the time constraints. ${ }^{[14]}$

\section{Wanton abuse}

The claim that wanton abuse of the $\mathrm{D}$ and $\mathrm{X}$ procedure might occur stems from the notion that $D$ and $X$ is performed electively on healthy fetuses. ${ }^{[14]}$ This argument is predicated on US congressional reports on three physicians, Martin Haskell, James McMahon and David Grundmann ${ }^{[14,42-46]}$ According to congressional reports, the physicians expressly conveyed their willingness to employ $D$ and $X$ owing to its convenience and efficacy, cumulatively performing thousands of the procedures that are erroneously referred to in the reports as PBAs. ${ }^{[1442-46]}$ Each physician allegedly confessed to performing the majority of $D$ and $X$ procedures electively on healthy fetuses. ${ }^{[14,44-46]}$ If $D$ and $X$ was cited for medical reasons, the fetuses suffered from neurological impairments and shallow defects that could be surgically improved or managed. ${ }^{[14,44]}$ Additionally, D and X was offered to patients on the grounds of fetal impairment, socioeconomic hardship and to adolescent minors by Grundmann. ${ }^{[14,44]}$

Wanton abuse as a ground for proscription of $D$ and $X$ is spurious. ${ }^{[14]}$ The argument does not exclusively apply to $D$ and $X$, as it can be applied to any surgical abortion procedure. ${ }^{[14]}$ For instance, a physician could favour $D$ and $E$ over induction of labour ( $(\mathrm{OL})$, since $D$ and $\mathrm{E}$ is a convenient and shorter outpatient procedure than IOL. ${ }^{[14,47]}$ Alternatively, the physician may opt for $\mathrm{IOL}$, a protracted inpatient abortion procedure that would probably yield more financial gain for the physician, even though $D$ and $E$ might be applicable. ${ }^{[14,48]}$ Similarly, the physician might prefer $D$ and $E$ to $D$ and $X$ for similar reasons. ${ }^{[14]}$ The evidence regarding wanton abuse is also meagre, considering that it is predicated on the alleged abuse by three physicians. ${ }^{[14]}$ It is irrational to proscribe $\mathrm{D}$ and $\mathrm{X}$ on the basis of convenience and simplicity when it is efficacious. Furthermore, the provision of abortion services to minors and on socioeconomic grounds is reflective of SA law. CTOPA strives to uphold women's constitutional rights, specifically the rights to bodily integrity and reproductive healthcare. ${ }^{[1435,36]}$ CTOPA allows abortion for a woman of any age, upon her consent. ${ }^{[49,50]}$ Abortion is available between 13 and 20 weeks' gestation once the physician, in consultation with the patient, has concluded that: the 
pregnancy will be detrimental to her physical or mental health; the fetus is at risk of acute physical or mental disability; conception was the product of rape or incest; or continued pregnancy will adversely affect her socioeconomic status. ${ }^{[14,51-54]}$

\section{Infanticide and neonaticide}

While breech presentation is a core element of $D$ and $X$, the National Abortion Federation claims that $\mathrm{D}$ and $\mathrm{X}$ may be performed via cephalic presentation, requiring physicians to collapse the fetal skull externally. ${ }^{[14,55]}$ If $\mathrm{D}$ and $\mathrm{X}$ were performed by cephalic presentation on a living fetus that takes its first breath before its demise, the physician would be guilty of neonaticide. ${ }^{[14]} \mathrm{D}$ and $\mathrm{X}$ is also reportedly performed without fetal anaesthesia. ${ }^{[14,56]}$ Accordingly, $D$ and $X$ opponents believe that the procedure blurs the lines between the crimes of infanticide and neonaticide, and abortion. It could be argued that $D$ and $X$ deprives the fetus of life on the cusp of personhood, in a bid to protect physicians from prosecution. ${ }^{[14]}$ According to the American Medical Association, the 'partial-birth' aspect of $D$ and $X$ confers the right to autonomy on the fetus, thereby fuelling the claim that $D$ and $X$ is essentially neonaticide. ${ }^{[14,57]}$

Nevertheless, it is important to familiarise ourselves with the definitions of neonaticide and infanticide before deciding if either crime encompasses $D$ and $X$. Neonaticide is the unlawful killing of a new-born child during the first week of its life, and infanticide is the unlawful killing of a child during the first year of its life. ${ }^{[58]}$ Abortion is the expulsion of the uterine contents, particularly the fetus. ${ }^{[20]}$ Legally, neonaticide and infanticide necessitate the killing of a person. According to the common law, in order to attain personhood and its accompanying rights, the child must be born alive and exist independently of its mother ${ }^{[58-61]}$ During $D$ and $X$, fetal demise transpires within the womb, if the fetus is alive. ${ }^{[14]}$ Thus, $D$ and $X$ does not constitute infanticide or neonaticide; killing the fetus is not an essential element of $D$ and $X$, as the procedure is often employed in cases of miscarriage. ${ }^{[17]}$ The majority of surgical abortion procedures available during each trimester incorporates fetal dismemberment, specifically: manual vacuum aspiration, suction and curettage, dilation and curettage and $D$ and $E .{ }^{[14,62-65]}$ The remaining procedures - IOL, hysterectomy and hysterotomy - usually employ feticidal solutions that generally asphyxiate and incinerate the fetus to effect fetal demise. ${ }^{[14,66,67]}$ Evidently, $D$ and $X$ is significantly less destructive, and perhaps more humane than most feticidal abortion procedures available. ${ }^{[14]}$ Moreover, evidence depicting $\mathrm{D}$ and $\mathrm{X}$ via cephalic presentation concerning living fetuses is scant; it is probable that $\mathrm{D}$ and $\mathrm{X}$ via cephalic presentation occurs in cases of miscarriage, considering it would be grossly unethical and unlawful to perform on a living fetus. ${ }^{[14]}$

\section{Conscientious objection}

Approximately $95 \%$ of South Africans are religious, often belonging to one of five prevalent religions: Christianity, African traditional religion, Islam, Hinduism and Judaism. ${ }^{[68]}$ All five religions condemn LTOP except in life-threatening circumstances. ${ }^{[14,69-75]}$ The right to freedom of conscience, religion, thought, belief and opinion is constitutionally protected in SA. ${ }^{[76]}$ Therefore, a physician may conscientiously object to performing an abortion outside of an emergency context, as long as another physician is willing and available to do so. ${ }^{[14,76,77]}$ CTOPA states that LTOP is permissible after 20 weeks' gestation once a physician who has consulted with another physician or registered nurse concludes that the pregnancy is life-threatening, the fetus is severely malformed or the fetus is at risk of being severely injured during birth. ${ }^{[22-25]}$ Therefore it could be argued that if $\mathrm{D}$ and $\mathrm{X}$ is not performed, in accordance with CTOPA, it may abridge the rights of the physician if the patient requests $D$ and $X$, or repudiate the rights of the patient if the physician elects to perform $D$ and $X$ and the patient does not consent to or refuses the procedure. ${ }^{[14]}$

Nevertheless, in SA a person is legally and ethically entitled to receive emergency medical care, irrespective of whether the person requiring emergency assistance is a patient of the physician administering the assistance. ${ }^{[14,77,78]}$ Accordingly, should a medical emergency arise necessitating LTOP, physicians are legally and ethically obligated to perform the LTOP, irrespective of the physician's right to conscientious objection, since it is unjustifiable in an emergency setting to deny a patient medical assistance. ${ }^{[14,78]}$ Failure to do so will give rise to legal consequences. ${ }^{[14,78]}$ In any other circumstances, a physician may conscientiously object to the procedure, only if another physician is readily available and willing to perform the procedure. ${ }^{[14,78]}$ Since $D$ and $X$ is an LTOP procedure employed from 20 weeks onwards, it is governed by section $2(1)(c)$ of CTOPA mentioned above. ${ }^{[22-25]}$ Consequently, a physician's right to conscientious objection is limited to the exceptional circumstances outlined in section 2(1)(c) of CTOPA. ${ }^{[22-25]}$ Failure to provide D and $X$ in an emergency will give rise to criminal liability if the patient is grievously harmed or dies. ${ }^{[14,78]}$

\section{Futility and unnecessary risks}

Some critics dispute the efficacy of $D$ and $X$ in medical emergencies. ${ }^{[79]} \mathrm{An}$ 'emergency' is defined as 'a dramatic, sudden situation or event, which is of a passing nature in terms of time', to the exclusion of chronic illnesses. ${ }^{\left[{ }^{[0]}\right.}$ Since emergencies are abrupt and unforeseeable, immediate medical assistance is obligatory. $D$ and $X$ is usually performed over 2 and 3 days owing to the process of gradual cervical dilation, hence the argument regarding its futility in medical emergencies. ${ }^{[5,79]}$ Additionally, D and X allegedly entails the risk of supplementary medical complications when compared with alternative LTOP procedures, particularly: ruptured uterus, abruption, amniotic fluid embolus, uterine trauma, iatrogenic laceration, secondary haemorrhage and infection. ${ }^{[81,82]}$ Therefore, there are allegedly no compelling reasons justifying its use. ${ }^{[14]}$

In actuality, $\mathrm{D}$ and $\mathrm{X}$ offers numerous safety benefits that have been certified by physicians and accepted by the US Supreme Court. ${ }^{[14,82,83]} D$ and $X$ diminishes the risk of cervical laceration, uterine perforation ${ }^{[14,83]}$ and vaginal penetration, reducing harm to patients with compromised immune systems and susceptible to uterine damage, including patients with chorioamnionitis. ${ }^{[14,83]} \mathrm{D}$ and $\mathrm{X}$ reduces cervical and uterine injuries associated with fetal dismemberment, as well as lifethreatening complications such as fetal tissue retention. ${ }^{[1482,83]}$ The procedure mitigates trauma, haemorrhage, anaesthesia and serious harm to patients with blood disorders. ${ }^{[14,83]} \mathrm{D}$ and $\mathrm{X}$ can be particularly salutary when severe malformation necessitates LTOP, such as in cases of hydrocephaly, an abnormality that can only be ascertained during the final stages of pregnancy. ${ }^{[1,83]}$ Hydrocephaly abnormally expands the diameter of the fetal skull to the point of severe brain 
damage. ${ }^{[79]}$ Cephalocentesis reduces the diameter of the fetal skull, permitting safe vaginal delivery, which would otherwise be lifethreatening. ${ }^{[79]} \mathrm{D}$ and $\mathrm{X}$ is an advantageous and necessary medical procedure, which is probably why the Partial-Birth Abortion Ban Act is inclusive of a health exception. ${ }^{[14-18]}$ The claim that $D$ and $X$ is futile in emergencies is implicitly flawed, as every LTOP procedure takes place over at least 2 days. ${ }^{[14]} \mathrm{D}$ and $\mathrm{E}$ usually occurs within 2 days, ${ }^{[84]}$ while IOL may last several days, given the complexity of the procedure. ${ }^{[49]}$ Based on the logic of this argument, D and $\mathrm{E}$ and IOL would both be considered futile in an emergency context. ${ }^{[14]}$ The alternative is either a hysterotomy or hysterectomy, which carry greater risks of maternal mortality than childbirth, and both procedures are contraindicated by the World Health Organization. ${ }^{[85]}$

\section{Proscription is constitutionally and ethically unjustifiable}

Proscription of $D$ and $X$ will infringe several constitutional and ethical rights of SA women. ${ }^{[14]}$ Proscription will deny women requiring LTOP vital information about and access to a medical procedure that could be beneficial and advantageous to their personal reproductive needs ${ }^{[14]}$ thereby infringing their rights to access to information and to reproductive healthcare. ${ }^{[14]}$ Consequently, women's right to bodily integrity will be breached, as their right to self-determination will be unnecessarily limited, ultimately repudiating patient autonomy. ${ }^{[14]}$ Furthermore, proscription will lead to unfair discrimination against patients suffering from autoimmune conditions and blood disorders, since $D$ and $X$ significantly reduces the health risks associated with these conditions. ${ }^{[14,86]}$ Consequently, proscription may jeopardise the lives of these patients. ${ }^{[14]}$ Should a women require emergency LTOP caused by hydrocephaly, D and $\mathrm{X}$ would be necessary to prevent grievous harm to and/or the death of the patient. ${ }^{[14,83]}$ Subsequently, proscription would infringe the right to emergency healthcare, and possibly the right to life if proscription is effected without a health exception. ${ }^{[14]}$

Proscription may force physicians into employing alternative LTOP procedures, consequently exacerbating the risk of failed LTOP. ${ }^{[14]}$ Should LTOP fail, the physician will be faced with performing either a hysterectomy or a hysterotomy, both of which are normally contraindicated as the risk of maternal mortality is greater than in childbirth. ${ }^{[14,85]}$ Subjecting the patient to multiple procedures that could otherwise be easily avoidable abridges the right to dignity of, and creates an undue burden on, the patient. ${ }^{[14]}$ Likewise, should the physician perform $D$ and $X$ to prevent unnecessary harm to the patient, he or she could face criminal liability and ultimately incarceration, even though the physician acted in the patient's best interest. ${ }^{[14]}$ Thus, proscription could arbitrarily infringe physicians' right to security of person. ${ }^{[14]}$

It is apparent that proscription of $D$ and $X$ would be an injudicious and unjustifiably restrictive policy that could undermine the Constitution and CTOPA, and subsequently increase maternal mortality and morbidity in SA. ${ }^{[14]}$ The proscription of $D$ and $X$ would not hinder the provision of abortion, as there are several surgical abortion procedures comprising feticide. ${ }^{[14]}$ Yet it could unnecessarily endanger the lives and health of those who may require $D$ and $X$. Therefore proscription is unethical and unconstitutional. ${ }^{[14]}$ Proscription of $D$ and $X$, a medically necessary, life-saving procedure, would bring about more harm than benefit to SA women. ${ }^{[14]}$ Furthermore, if $D$ and $\mathrm{X}$ were to be proscribed, it would probably be accompanied by a health exception permitting the procedure in emergency circumstances. This would render the proscription redundant, as $D$ and $X$ is an LTOP procedure that is performed after 20 weeks' gestation, and as previously mentioned, CTOPA specifies that LTOP is already restricted to the medical emergencies outlined in section 2(1)(c) above. ${ }^{[14,22-25]}$

Moreover, $\mathrm{D}$ and $\mathrm{X}$, because it allows the appropriate religious burial ceremonies to be conducted for an intact fetus, in comparison with more destructive abortion procedures, upholds the right to freedom of religion. According to SA law, if a child is stillborn after 26 weeks, registration is required for the child's death. ${ }^{[1,87]}$ Once the death is registered, a burial order will be issued to its parents, who are entitled to hold a burial ceremony for their child. ${ }^{[14,88]}$ Monotheistic religions and African traditional religious ceremonial burial practices require believers to cleanse and carefully clothe the deceased in sheaths preceding burial, while Hinduism calls for water burials or land burials for young children. ${ }^{[14,89-94]} \mathrm{D}$ and $\mathrm{X}$ is arguably the least destructive LTOP procedure, which delivers the fetus intact, rendering it the most appropriate procedure for religious burials. ${ }^{[14]}$ Although IOL, hysterectomies and hysterotomies may be used, feticidal solutions and agents utilised during the procedure tend to visibly destroy the fetus, ${ }^{[14,95,96]}$ which could exacerbate the trauma of losing a loved one. ${ }^{[14]}$ Hence, $D$ and $X$ may comply with the right to religious freedom, by allowing religious ethics to be complied with in a less traumatic manner. ${ }^{[14]}$

One cannot stress the significance of safeguarding and endorsing women's constitutional and reproductive rights enough, specifically against the background of the oppressive environment of our nation's divided past. The law at the time stripped women of their reproductive rights and exacerbated maternal morbidity and mortality for decades, before the introduction of our Constitution and CTOPA. ${ }^{[14]}$ The latter went to great lengths to undo the injustices of the past, enabling women to reclaim their constitutional and reproductive rights and, with the help of the judiciary, safeguard those rights and promote women's reproductive interests. ${ }^{[14]}$ Proscription of $D$ and $X$ or any feticidal abortion procedure could jeopardise the legacy that we have fought arduously as a nation to achieve.

\section{Recommendations}

While $\mathrm{D}$ and $\mathrm{X}$ is therefore constitutionally and ethically justifiable, there are alternative measures capable of inducing painless fetal demise that could be used in conjunction with LTOP procedures to effect abortion. ${ }^{[14]}$ It is submitted that physicians should incorporate the feticidal agent intracardiac potassium chloride, to achieve fetal demise prior to performing LTOP. ${ }^{[14]}$ Administration of the agent into the left ventricle of the heart will culminate in asystole, ensuring painless fetal demise. ${ }^{[14,97]}$ Thereafter the physician should perform the LTOP procedure that has been consented to by the patient. ${ }^{[14]}$ Alternatively, where LTOP does not necessitate D and $X$ to avert irreparable harm, or death to the patient, or because of fetal malformation, and the patient wishes to deliver the fetus, provided it is safe to do so, physicians should utilise neonatal palliative care (NPC). ${ }^{[14]}$ NPC strives to prevent and alleviate the pain and suffering of neonates. ${ }^{[14,98]}$ It is usually reserved in cases 
involving extremely premature neonates of 23 weeks and younger who are in need of intensive care, neonates with lethal conditions, including anencephaly, or neonates experiencing unbearable pain, and treatment is futile. ${ }^{[14,99]}$

\section{Conclusion}

In conclusion, proscribing $\mathrm{D}$ and $\mathrm{X}$, or any abortion procedure for that matter, is otiose. ${ }^{[14]}$ Proscription of specific abortion procedures appears to be an attempt to circumscribe abortion; however, there will always be other opportunities for physicians to effectuate feticide, provided abortion is legal. ${ }^{[14]}$ Furthermore, there is no point in proscribing $D$ and $X$ with the inclusion of a health exception, since LTOP in general is already reserved for rare circumstances that qualify as medical emergencies, as per CTOPA. ${ }^{[22-25]}$ Accordingly, proscription is redundant and impracticable. The arguments buttressing proscription are applicable to all surgical abortion procedures available to physicians in every trimester. ${ }^{[14]}$ Therefore, these arguments cannot be applied exclusively to any surgical abortion procedure, as all are feticidal by definition. ${ }^{[14]}$ Consequently, all surgical abortion procedures would be susceptible to proscription, which is untenable, unethical and unconstitutional. ${ }^{[14]}$

In actuality, 'PBA' is not a medical procedure; it is a term coined by anti-abortion advocates to refer to $D$ and $X_{r}^{[2]}$ a medically necessary, life-saving abortion procedure that enables women to exercise their constitutional, legal and ethical rights, and it could potentially reduce the rates of maternal morbidity and mortality in SA. ${ }^{[14]}$ It should be readily considered and used by physicians in the appropriate circumstances, as it is not a procedure generally known to be practised in $S A .{ }^{[14]} D$ and $X$ should be practised without any possibility of legal repercussions in SA. Any attempt to regulate feticide via the circumscription of a particular surgical abortion procedure could thwart access to safe and legal abortion in SA. ${ }^{[14]}$

However, there are ways in which to humanely induce fetal demise before LTOP. It is recommended that physicians utilise the feticidal agent intracardiac potassium chloride to achieve painless fetal demise ${ }^{[97]}$ in conjunction with the LTOP procedure consented to by the patient, including $D$ and X. Alternatively, physicians should employ NPC when LTOP is not required, or when the patient refuses LTOP and her health permits her to deliver the fetus. NPC is specifically recommended in cases where the neonate is extremely premature, suffers from a lethal condition or is subjected to unbearable pain, and treatment is futile. ${ }^{[98,99]}$

Acknowledgements. None.

Author contributions. Sole author.

Funding. None.

Conflicts of interest. None.

1. Hull NEH, Hoffer PC. Roe v Wade: The Abortion Rights Controversy in American History. 2nd ed. Lawrence: University Press of Kansas, 2010.

2. Hames JB, Ekern Y. Constitutional Law: Principles and Practice. 2nd ed. Clifton Park: Delmar Cengage Learning, 2013.

3. Saletan W. Bearing Right: How Conservatives Won the Abortion War. Berkeley: University of California Press, 2004

4. White ML. Of Science and God. Bloomington: Xlibris Corporation, 2012

5. Lohr PA, Lyus R. Dilation and evacuation. In: Rowlands S, ed. Abortion Care. Cambridge: Cambridge University Press, 2014;88-97.

6. Oswalt SB. Exploring the Dimensions of Human Sexuality. 5th ed. Burlington: Jones \& Bartlett, 2014
7. Middleberg MI. Promoting Reproductive Security in Developing Countries. New York: Kluwer, 2004

8. Fritz MA, Speroff L. Clinical Gynecologic Endocrinology and Infertility. Philadelphia: Lippincott Williams \& Wilkins, 2011.

9. Chasen ST, Chervenak F, McCullough LB. The role of cephalocentesis in modern obstetrics. Am J Obstetr and Gynecol 2001;185(3):734-736. https://doi. org/10.1067/mob.2001.117487

10. Von Hagel A, Mansbach D. Reproductive Rights in the Age of Human Rights: Prolife Politics from Roe to Hobby Lobby. New York: Palgrave MacMillan, 2016.

11. Lu MC. Induced Abortion. In: Pregler JP, DeCherney AH. Women's Health: Principles and Clinical Practice. Hamilton: BC Decker, 2002;228-236.

12. Ehrenreich N. The Reproductive Rights Reader: Law, Medicine and the Construction of Motherhood. New York: New York University Press, 2008.

13. Guttmacher Institute. State Policies in Brief: Bans on "Partial-Birth" Abortion, 2016. http://www.guttmacher.org/statecenter/spibs/spib_BPBA.pdf (accessed 7 November 2017).

14. Jogee F. The Legal and Ethical Implications of Implementing Partial-Birth Abortion in South Africa. LLM thesis. Durban: University of KwaZulu-Natal, 2017.

15. Ainsworth SH, Hall TE. Abortion Politics in Congress: Strategic Incrementalism and Policy Change. Cambridge: Cambridge University Press, 2011.

16. Leo J.Two Steps Ahead of the Thought Police. 2nd ed. New Brunswick: Transaction Publishers, 1998.

17. James DK, Steer PJ, Weiner CP, et al, eds. High Risk Pregnancy Management Options. 4th ed. St. Louis: Elsevier/Saunders, 2010.

18. United States of America. Partial-Birth Abortion Ban Act of 2003. Pub.L.108-105, 117 Stat. 1201, enacted November 5, 2003, 18 U.S.C. 1531.

19. Gonzales v Carhart 550 U.S. 124, 2007.

20. South Africa. The Choice on Termination of Pregnancy Act No. 92 of 1996.

21. Morna CL, Makaya-Magarangoma M. The impact of women's political leadership on democracy and development in South Africa. In: Commonwealth Secretariat. The Impact of Women's Political Leadership on Democracy and Development Case Studies from the Commonwealth, 2013;7-38.

22. South Africa. The Choice on Termination of Pregnancy Act No. 92 of 1996. Section 2(1)(c).

23. South Africa. The Choice on Termination of Pregnancy Act No. 92 of 1996. Section 2(1)(c)(i).

24. South Africa. The Choice on Termination of Pregnancy Act No. 92 of 1996. Section 2(1)(c)(ii).

25. South Africa. The Choice on Termination of Pregnancy Act No. 92 of 1996. Section 2(1)(c)(iii).

26. Derbyshire SWG. Can fetuses feel pain? BMJ 2006;332(7546):909-912. https://doi. org/10.1136/bmj.332.7546.909.

27. Van de Velde $M$, De Buck F. Fetal and maternal analgesics/anesthesia for fetal procedures. Fetal Diagn Ther 2012;31(4):201-209. https://doi. org/10.1159/000338146

28. Myers LB, Bulich LA, Hess $P$, et al. Fetal endoscopic surgery: Indications and anaesthetic management. Best Prac ResClin Anaesthesiol 2004;18(2):231-258. https://doi.org/10.1016/j.bpa.2004.01.001

29. Rosen, MA. Anesthesia for Fetal Surgery and Other Intrauterine Procedures. In: Chestnut DH, Polley L, Wong C, et al, eds. Chestnut's Obstetric Anesthesia: Principles and Practice. 4th ed. Philadelphia: Elsevier/Mosby, 2009;123-140.

30. Lee SJ, Ralston HJ, Drey EA, et al. A systematic multidisciplinary review of the evidence. JAMA 2005;294(8): 947-954. https://doi.org/10.1001/jama.294.8.94724

31. National Abortion Federation, et al v Ashcroft Transcripts Tr. New York: Day 11 page 54:14-23 (Anand), page 60:13-17 (Anand). www.priestsforlife.org/pba/ nyhighlights.pdf (accessed 7 November 2017)

32. Joseph R. Human Rights and the Unborn Child. Leiden: Martinus Nijhoff Publishers, 2009

33. Lowery $\mathrm{CL}$, Hardman MP, Manning $\mathrm{N}$, et al. Neurodevelopmental changes of fetal pain. Semin Perinatol 2007;3(5):275-282. https://doi.org/10.1053/j semperi.2007.07.004

34. National Abortion Federation, et al v Ashcroft 03 Civ. 8695 (RCC).

35. South Africa. The Constitution of the Republic of South Africa Act No. 108 of 1996. Section 12(1).

36. South Africa. The Constitution of the Republic of South Africa Act No. 108 of 1996 Section 27.

37. South Africa. The Constitution of the Republic of South Africa Act No. 108 of 1996. Section 32(1).

38. Singh JA. Law and the health professional in South Africa. In: Moodley K, ed. Medical Ethics, Law and Human Rights: a South African Perspective. 2nd ed. Pretoria: Van Schaik Publishers, 2017;129-166.

39. South Africa. National Health Act No. 63 of 2003. Section 6(1).

40. South Africa. National Health Act No. 63 of 2003. Section 6(2).

41. South Africa. National Health Act No. 63 of 2003. Section 8(3). 
42. Haskell M. Dilation and Extraction for Late Trimester Abortion. Presented at the National Abortion Federation Risk Management Seminar, 13 September 1992. http://www.sharonvilleclinic.com/uploads/6/2/0/0/6200039/idx.pdf (accessed 7 November 2017).

43. Gerard FB. Abortion - Murder or Mercy? Analysis and Bibliography. Huntington: Nova Science Publishers, 2001

44. Congressional Record - Extension of Remarks. A Closer Look at Partial-Birth Abortions. Hon. Robert K Dornan of California in the House of Representatives. September 1997.

45. Garrow DJ. Liberty and Sexuality: The Right to Privacy and the Making of Roe v Wade. Berkeley: University of California Press, 1998.

46. Leo J. Incorrect Thoughts: Notes on Our Wayward Culture. New Brunswick: Transaction Publishers, 2001.

47. Shaw KA, Lerma K. Update on second-trimester surgical abortion. Curr Opin Obstetr Gynecol 2016;28(6):510-516. https://doi.org/10.1097/gco.0000000000000318

48. Callahan TL, Caughey AB. Blueprints in Obstetrics and Gynecology. 6th ed. Philadelphia:Wolters Kluwer/Lippincott Williams \& Wilkins Health, 2013.

49. South Africa. The Choice on Termination of Pregnancy Act No. 92 of 1996. Section $5(1)$.

50. South Africa. The Choice on Termination of Pregnancy Act No. 92 of 1996. Section $1(\mathrm{xi})$

51. South Africa. The Choice on Termination of Pregnancy Act No. 92 of 1996. Section 2(1)(b)(i).

52. South Africa. The Choice on Termination of Pregnancy Act No. 92 of 1996. Section 2(1)(b)(ii)

53. South Africa. The Choice on Termination of Pregnancy Act No. 92 of 1996. Section 2(1)(b)(iii).

54. South Africa. The Choice on Termination of Pregnancy Act No. 92 of 1996. Section 2(1)(b)(iv).

55. Paul M, Lichentenberg S, Borgatta $L$, et al. Management of Unintended and Abnormal Pregnancy: Comprehensive Abortion Care. Chichester: Wiley-Blackwell, 2009.

56. Schwarz SD, Latimer K. Understanding Abortion: From Mixed Feelings to Rational Thought. Lanham: Lexington Books, 2012

57. AMA Board of Trustees Factsheet on H.R. 1122 (June 1997), in App. to Brief to Association of American Physicians and Surgeons et al. as Amici Curiae.

58. Mathews S, Martin LJ, Coetzee, et al. Child deaths in South Africa: Lessons from the child death review pilot. S Afr Med J 2016;106(9):851-852. http://doi.org/10.7196/ samj.2016.v106i9.11382

59. Boezaart T. The Law of Persons. 5th ed. Cape Town: Juta, 2010.

60. Cronje DSP, Heaton J. The South African Law of Persons. 3rd ed. Durban: LexisNexis, 2008

61. Pillay R. The beginning of human personhood: Is South African law outdated? Stellenbosch Law Rev 2010;2:230-238.

62. Hamoda $\mathrm{H}$, Flett GM, Ashok PW, et al. A surgical abortion using manual vacuum aspiration under local anaesthesia: A pilot study of feasibility and women's acceptability. J Fam Plann Reprod Health Care 2005;31(3):185-188. https://doi. org/10.1783/1471189054484004

63. Gupta R, Kilby M, Cooper G. Fetal surgery and anaesthetic implications. CEACCP 2008;8(2):71-75. https://doi.org/10.1093/bjaceaccp/mkn004

64. Beckmann CRB, Ling FW, Barzansky BM, et al. Obstetrics and Gynecology. 6th ed. Philadelphia: Wolters Kluwer/ Lippincott Williams \& Wilkins, 2010.

65. Chou D, Ural S. Operative obstetrics. In: Morgan M, Siddighi S, editors. Obstetrics and Gynecology. 5th ed. Philadelphia: Lippincott Williams \& Wilkins, 2005:130-145.

66. Alcorn R. Pro-Life Answers to Pro-Choice Arguments - Expanded \& Updated. Colorado Springs: Multnomah Books, 2000.

67. Sharma P. Midwifery and Obstetrical Nursing. New Delhi: Gennext Publication, 2010.

68. Statistics South Africa. Statistical Release P0318 - Household Survey 2015, 2016. http://www.statssa.gov.zapublicationsP0318P03182015.pdf (accessed 7 November 2017).

69. Schiff D. Abortion in Judaism. Cambridge: Cambridge University Press, 2002.
70. Kelly DF, Magill G, Have HT. Contemporary Catholic Health Care Ethics. 2nd ed. Washington: Georgetown University Press, 2013.

71. Pauls M, Hutchinson RC. Protestant bioethics. In: Singer PA, Viens AM, editors. The Cambridge Textbook of Bioethics. Cambridge: Cambridge University Press, 2008:430-435.

72. Shanawani H, Khalil MH. Reporting on 'Islamic bioethics' in the medical literature: Where are the experts? In: Brockopp JE, Eich T, editors. Muslim Medical Ethics: From Theory to Practice. Columbia: University of South Carolina Press, 2008:213-228.

73. Alamri YA. Islam and abortion. J IMA 2011;43(1):39-40. http://doi.org/10.5915/431-5755

74. Bailey J. Abortion. New York: Rosen Publishing Group Inc, 2012.

75. Rakhudu MA, Mmelesi AM, Myburgh CP, et al. Exploration of the views of traditional healers regarding the termination of pregnancy (TOP) law. Curationis 2006;29(3):56-60. http://doi.org/10.1111/j.1365-2702.2007.02205.x/abstract

76. South Africa. The Constitution of the Republic of South Africa Act No. 108 of 1996. Section 15(1).

77. South Africa. The Constitution of the Republic of South Africa Act No. 108 of 1996 Section 27(3).

78. McQuoid-Mason D. State doctors, freedom of conscience and termination of pregnancy revisited. S Afr J Bioethics Law 2010;3(2):75-78.

79. Kuhne CC. Building Your Best Argument. Chicago: ABA Publishing, 2010.

80. Soobramoney v Minister of Health (Kwazulu-Natal) 1998 (1) SA 765 (CC).

81. Cawthon EA. Medicine on Trial: A Handbook with Cases, Laws, and Documents. Santa Barbara: ABC-CLIO, 2004

82. Stenberg v Carhart 530 U.S. 914,2000

83. National Abortion Federation, et al v Ashcroft 03 Civ. 8695 (RCC) Ruling and opinion. http://prochoice.org/wp-content/uploads/naf_v_ashcroft_ruling_pdf (accessed 7 November 2017).

84. Brien J, Fairbairn I. Pregnancy and Abortion Counselling. London: Routledge, 1996.

85. World Health Organization, Department of Reproductive Health and Research. Safe Abortion: Technical and Policy Guidance for Healthy Systems. 2nd ed. Geneva: WHO, 2012. http://apps.who.int/iris/bitstream/10665/70914/1/9789241548434 eng.pdf (accessed 7 November 2017).

86. Ruse C. Partial-birth abortion on trial. Human Life Review 2006;31(2):87-104.

87. South Africa. Birth and Deaths Registration Act No. 51 of 1992. Section 1.

88. South Africa. Birth and Deaths Registration Act No. 51 of 1992. Section 18.

89. Jerrett Z. Sub-Saharan Africa: West Africa. In: Joseph S, Nagmabadi A, editors. Encyclopedia of Women and Islamic Cultures: Family, Body, Sexuality and Health, Volume 3. Leiden: Brill, 2006:125-128.

90. Keene M. This is Judaism. Cheltenham: Stanley Thornes, 1996.

91. Sheard DJ. Daily Life in Arthurian Britain. Santa Barbara: Greenwood, 2013.

92. Michaels A. Hinduism: Past and Present. Princeton, NJ: Princeton University Press, 2004.

93. Hindmarch C On the Death of a Child. 3rd ed. Abigdon: Radcliffe Publishing, 2009.

94. Agorsah EK, Childs GT. Africa and the African Diaspora: Cultural Adaptation and Resistance. Bloomington: Author House, 2006.

95. Cox FD, Demmit K. Human Intimacy: Marriage, the Family, and its Meaning. 11th ed. Belmont: Wadsworth Cengage Learning, 2014

96. Martinelli-Fernandez S, Baker-Sperry L, Mcllvaine-Newsad H, editors. Interdisciplinary Views on Abortion: Essays from Philosophical, Sociological, Anthropological, Political, Health and Other Perspectives. Jefferson: McFarland, 2009.

97. Govender L, Moodley J. Late termination of pregnancy by intracardiac potassium chloride injection: 5 years' experience at a tertiary referral centre. S Afr Med J 2013;103(1):47-51.

98. Caitlin A, Carter B. Creation of a neonatal end-of-life palliative care protocol. J Perinatol 2002:22(3):184-195.

99. Warrick C, Perera L, Murdoch E, et al. Guidance for withdrawal and withholding of intensive care as part of end-of-life care. Brit Med Bull 2011;98(1):99-113. https:// doi.org/10.1093/bmb/ldr016

Accepted 17 May 2018 